(c) Copyright, Princeton University Press. No part of this book may be

distributed, posted, or reproduced in any form by digital or mechanical means without prior written permission of the publisher.

\title{
One
}

\section{The Stock Market in \\ Historical Perspective}

W

hen Alan Greenspan, then Chair of the Federal Reserve Board, used the term

irrational exuberance to describe the behavior of stock market investors, the world fixated on those words. ${ }^{1}$ He spoke at a black-tie dinner in Washington, D.C., on December 5, 1996, and the televised speech was followed the world over. As soon as he uttered these words, stock markets dropped precipitously. In Japan, the Nikkei index dropped 3.2\%; in Hong Kong, the Hang Seng dropped 2.9\%; and in Germany, the DAX dropped $4 \%$. In London, the FTSE 100 was down $4 \%$ at one point during the day, and in the United States, the next morning, the Dow Jones Industrial Average was down 2.3\% near the beginning of trading. The sharp reaction of the markets all over the world to those two words in the middle of a staid and unremarkable speech seemed absurd. This event made for an amusing story about the craziness of markets, a story that was told for a time around the world.

The amusing story was forgotten as time went by, but not the words irrational exuberance, which were referred to again and again. Greenspan did not coin the phrase irrational exuberance, but he did cause it to be attached to a view about the instability of speculative markets. The chain of stock market events caused by his uttering these words made the words seem descriptive of essential reality. Gradually they became Greenspan's most famous quotea catch phrase for everyone who follows the market.

Why do people still refer so much to irrational exuberance years later? I believe that the words have become a useful name for the kind of social phenomenon that perceptive people saw with their own eyes happening in 
(c) Copyright, Princeton University Press. No part of this book may be distributed, posted, or reproduced in any form by digital or mechanical means without prior written permission of the publisher.

the 1990s, and that in fact, it appears, has happened again and again in history, when markets have been bid up to unusually high and unsustainable levels under the influence of market psychology.

Many perceptive people were remarking, as the great surge in the stock market of the 1990s continued, that there was something palpably irrational in the air, and yet the nature of the irrationality was subtle. There was not the kind of investor euphoria or madness described by some storytellers, who chronicled earlier speculative excesses like the stock market boom of the 1920s. Perhaps those storytellers were embellishing the story. Irrational exuberance is not that crazy. The once-popular terms speculative mania or speculative orgy seemed too strong to describe what we were going through in the 1990s. It was more like the kind of bad judgment we all remember having made at some point in our lives when our enthusiasm got the best of us. Irrational exuberance seems a very descriptive term for what happens in markets when they get out of line.

Irrational exuberance is the psychological basis of a speculative bubble. I define a speculative bubble as a situation in which news of price increases spurs investor enthusiasm, which spreads by psychological contagion from person to person, and, in the process, amplifies stories that might justify the price increase and brings in a larger and larger class of investors, who, despite doubts about the real value of the investment, are drawn to it partly through envy of others' successes and partly through a gambler's excitement. We will explore the various elements of this definition of a bubble throughout this book.

Greenspan's "irrational exuberance" speech in 1996 came during the biggest historical example to date of a speculative upsurge in the U.S. stock market. The Dow Jones Industrial Average (from here on, the Dow for short) stood at around 3,600 in early 1994. By March 1999, it passed 10,000 for the first time. The Dow peaked at 11,722.98 in January 14, 2000, just two weeks after the start of the new millennium. The market had tripled in five years. Other stock price indices peaked a couple of months later. The real (inflation-corrected) Dow did not reach this level again until 2014, and, as of this writing, the real Standard \& Poor's 500 index has still not quite returned to its 2000 level. It is curious that this peak of the Dow (as well as other indices) occurred in close proximity to the end of the celebration of the new millennium-it was as if the celebration itself was part of what had propelled the market, and the hangover afterward had brought it back down.

Figure 1.1 shows the monthly real (corrected for inflation using the Consumer Price Index) Standard and Poor's (S\&P) Composite Stock Price Index, a more comprehensive index of stock market prices than the Dow, based, since 1957, on 500 stocks rather than just the 30 stocks that are used to compute the Dow. ${ }^{2}$ Inflation correction was used here because the overall 
(c) Copyright, Princeton University Press. No part of this book may be distributed, posted, or reproduced in any form by digital or mechanical means without prior written permission of the publisher.

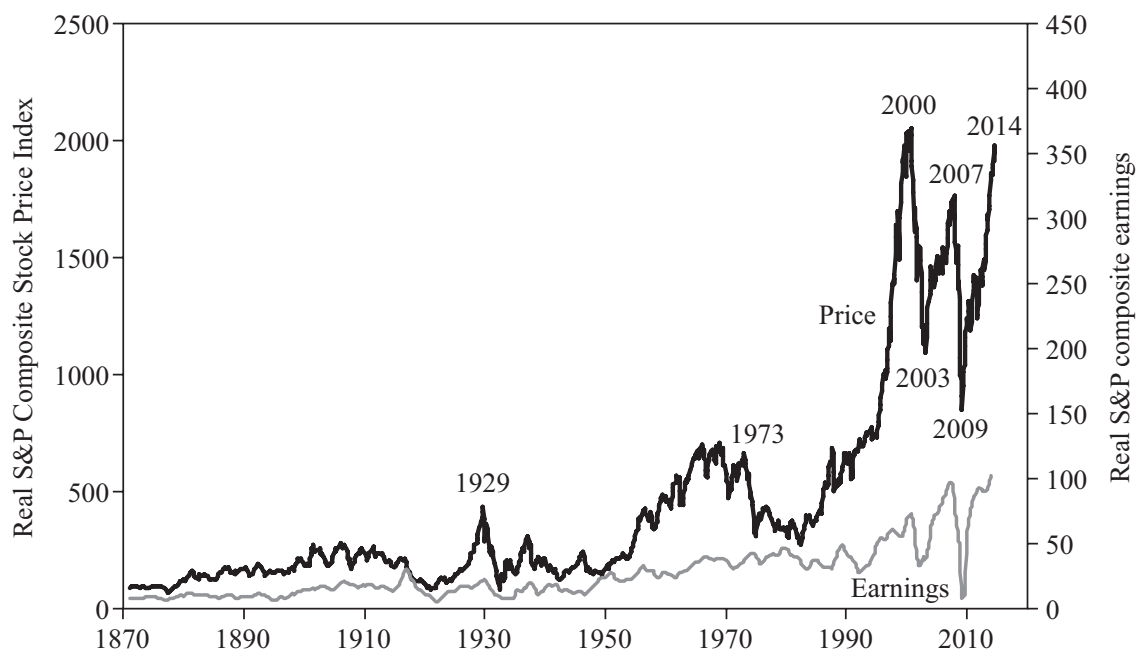

Figure 1.1

\section{U.S. Stock Prices and Earnings, 1871-2014}

Real (inflation-corrected) S\&P Composite Stock Price Index, monthly, January 1871 through June 2014 (upper curve), and real S\&P Composite earnings (lower curve), January 1871 to March 2014. Source: Author's calculations using data from S\&P Statistical Service; U.S. Bureau of Labor Statistics; Cowles and associates, Common Stock Indexes; and Warren and Pearson, Gold and Prices. See also note 3.

level of prices has been very unstable over parts of this period (the government printed a lot of money, which pushed all prices up) so that the uncorrected numbers would give a misleading impression of the real increase in the stock market. The stock prices are shown from 1871 through 2014 (upper curve), along with the total earnings (corporate profits per share) that the corporations that comprise the index made in doing their businesses (lower curve) for the same years. ${ }^{3}$

This stock market chart is unusual: most long-term plots of stock prices are not this long term, and most are done in nominal terms, without inflation correction. On this chart, the magnitude of the boom beginning in 1982 and peaking in 2000 stands out especially well. It is a unique event in history.

The 2000 Millennium Boom peak in world stock prices was followed by the Ownership-Society Boom, 2003-7, which I have named after a slogan used by George Bush in his 2004 presidential campaign. This peak was followed by the world financial crisis in 2008-9. Starting in 2009, after the crisis lessened, there was another major upswing in world stock markets, which I will call the New-Normal Boom, after a phrase popularized by Bill Gross, then of PIMCO, in 2009. 4 The news media have shown a tendency since 2000 to dramatize the 
(c) Copyright, Princeton University Press. No part of this book may be distributed, posted, or reproduced in any form by digital or mechanical means without prior written permission of the publisher.

"new records" set in stock markets in 2007 and 2014. But, in fact, these post2000 booms were not record setting. The biggest-ever upswing in the real (inflation-corrected) U.S. stock market was from July 1982 to August 2000, when the market went up 7.7-fold, dwarfing the 5.2-fold upswing from December 1920 to September 1929, and also dwarfing the 5.1-fold upswing from June 1949 to December 1968. The upswings from 2003 to 2007 (1.5-fold) and from 2009 to 2014 (2.3-fold) are mild by comparison. For the purpose of understanding irrational exuberance, I will emphasize the 1982-2000 Millennium Boom, particularly its later years, when this exuberance became most palpable.

The stock market increase from 1994 (when the real stock market had already more than doubled since 1982) to 2000 could not obviously be justified in any reasonable terms. Basic economic indicators did not come close to tripling. Over the same interval, U.S. gross domestic product rose less than $40 \%$, and corporate profits rose less than $60 \%$, and that from a temporary recession-depressed base. Viewed in the light of these figures, the stock price increase appears unwarranted.

Large stock price increases occurred in many countries at around the same time, and the peaks in the stock markets were often roughly simultaneous in many countries in early 2000. Figure 1.2 shows the paths of stock prices for ten countries and for the world as a whole from 1995 to 2014. As can be seen from Figure 1.2, between 1995 and 2000 the real stock market valuations of Brazil, France, China, and Germany roughly tripled, while that of the United Kingdom roughly doubled. In 1999, the year before the peak, real stock price increases averaged $58 \%$ over the ten countries shown in Figure 1.2. The prices of all countries went up sharply in 1999; in fact, the smallest increase, occurring in the United Kingdom, was still an impressive 16\%. Stock markets in Asia (Hong Kong, Indonesia, Japan, Malaysia, Singapore, and South Korea) and Latin America (Chile and Mexico) also made astounding gains in 1999. It was a truly spectacular worldwide stock market boom.

The end of the 2000 boom brought stock markets down across much of the world by 2003, as can be seen in Figure 1.2. Once again, the next boom, peaking in late 2007 or early 2008, had huge impacts over much of the world. After that, the world slipped into the most serious recession since the Great Depression of the 1930s, economic growth rates faltered, and the post-bubble weakness of the world economy continued for years after. Despite the weakness of the world economy, the third stock market boom that began around 2009 affected many countries.

Looking back to Figure 1.1, which shows a longer history for the S\&P Index, we can see how differently the market behaved up to 2000 compared with the long past. The spiking of prices in the years 1982 through 2000 was most remarkable: the price index looks like a rocket taking off through the top of 
(c) Copyright, Princeton University Press. No part of this book may be distributed, posted, or reproduced in any form by digital or mechanical means without prior written permission of the publisher.

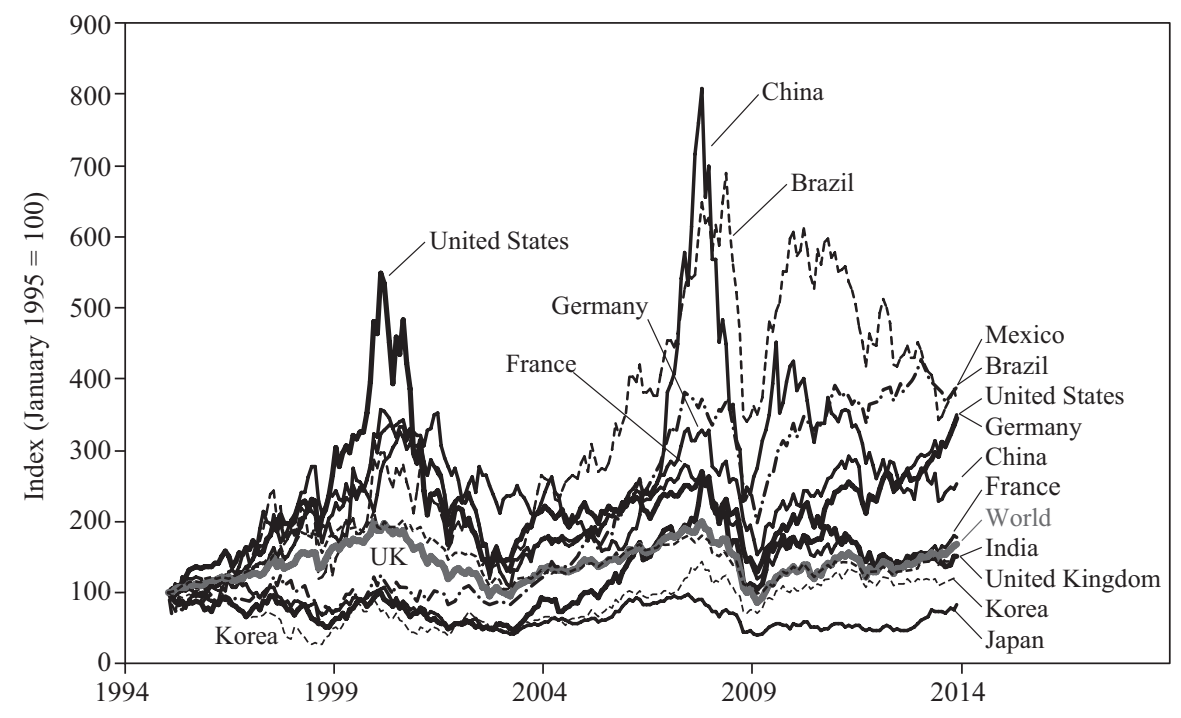

Figure 1.2

\section{Real Stock Prices in Ten Countries and the World, January 1995-July 2014}

Monthly closing prices in Brazil (Bovespa), China (SE Shang Composite), France (CAC), Germany (DAX), India (Sensex), Japan (Nikkei), Korea (KOSPI), Mexico (Mexbol), United Kingdom (FTSE 100), the United States (NASDAQ Composite), and the Morgan-Stanley Capital International All Country World Index, all deflated by the monthly Consumer Price Index for the currency, all rescaled to January 1995 = 100. Source: Bloomberg and International Monetary Fund International Financial Statistics (1999).

the chart, only to sputter and crash. This-the largest stock market boom ever-may be referred to as the Millennium Boom or, now that it is over, the Millennium Bubble. ${ }^{5}$

The boom and crash in the stock market in the years after 1994 are clearly related to the behavior of earnings. As can be seen in Figure 1.1, S\&P Composite earnings grew very fast in the late 1990s before they crashed after 2000, rose again until 2007, utterly crashed in 2009, and then rose with the market. Earnings seem to have been oscillating around a slow, steady growth path that has persisted for over a century.

Inspection of Figure 1.1 should make it clear that nothing like the Millennium Boom had ever happened before in the entire stock market history since 1871 . There was of course the famous stock run-up of the 1920s, culminating in the 1929 crash. Figure 1.1 reveals this boom as a cusp-shaped price pattern for those years. If one corrects for the market's smaller scale then, 
(c) Copyright, Princeton University Press. No part of this book may be distributed, posted, or reproduced in any form by digital or mechanical means without prior written permission of the publisher.

one recognizes that this episode in the 1920s does somewhat resemble the recent stock market increase, but it is the only historical episode that comes even close to being comparable.

\section{Price Relative to Earnings}

Figure 1.3 shows the cyclically adjusted price-earnings ratio (CAPE), that is, the real (inflation-corrected) S\&P Composite Index divided by the ten-year moving average of real earnings on the index. The points shown reflect monthly data from January 1881 to June $2014 .{ }^{6}$ The price-earnings ratio is a measure of how expensive the market is relative to an objective measure of the ability of corporations to earn profits. John Campbell and I originally defined CAPE using the ten-year average, along lines proposed by Benjamin Graham and David Dodd in $1934 .^{7}$

The ten-year average smooths out such events as the temporary burst of earnings during World War I, the temporary decline in earnings during World War II, and the frequent boosts and declines that we see due to the business cycle. ${ }^{8}$ Note again that there was an enormous spike after 1997, when the ratio rose until it hit 47.2 intraday on March 24, 2000. Price-earnings ratios by this measure had never been so high. The closest parallel was September 1929, when the ratio hit 32.6.

In 2000 earnings were quite high in comparison with the Graham and Dodd measure of long-run earnings, but nothing here was startlingly out of the ordinary. What was extraordinary in 2000 was the behavior of price (as also seen in Figure 1.1), not earnings.

Part of the explanation for the remarkable price behavior between 1990 and 2000 may have to do with the unusual behavior of corporations' profits as reflected in their earnings reports. Many observers remarked then that earnings growth in the five-year period ending in 1997 was extraordinary: real S\&P Composite earnings more than doubled over this interval, and such a rapid five-year growth of real earnings had not occurred for nearly half a century. But 1992 marked the end of a recession during which earnings were temporarily depressed. ${ }^{9}$ Similar increases in earnings growth following periods of depressed earnings from recession or depression have happened before. In fact, there was more than a quadrupling of real earnings from 1921 to 1926 as the economy emerged from the severe recession of 1921 into the prosperous Roaring Twenties. Real earnings doubled during the five-year periods following the depression of the 1890s, the Great Depression of the 1930s, and World War II.

It was tempting for observers in 2000, at the peak of the market, to extrapolate this earnings growth and to believe that some fundamental changes in the economy had produced a new higher growth trend in earnings. 
(c) Copyright, Princeton University Press. No part of this book may be distributed, posted, or reproduced in any form by digital or mechanical means without prior written permission of the publisher.

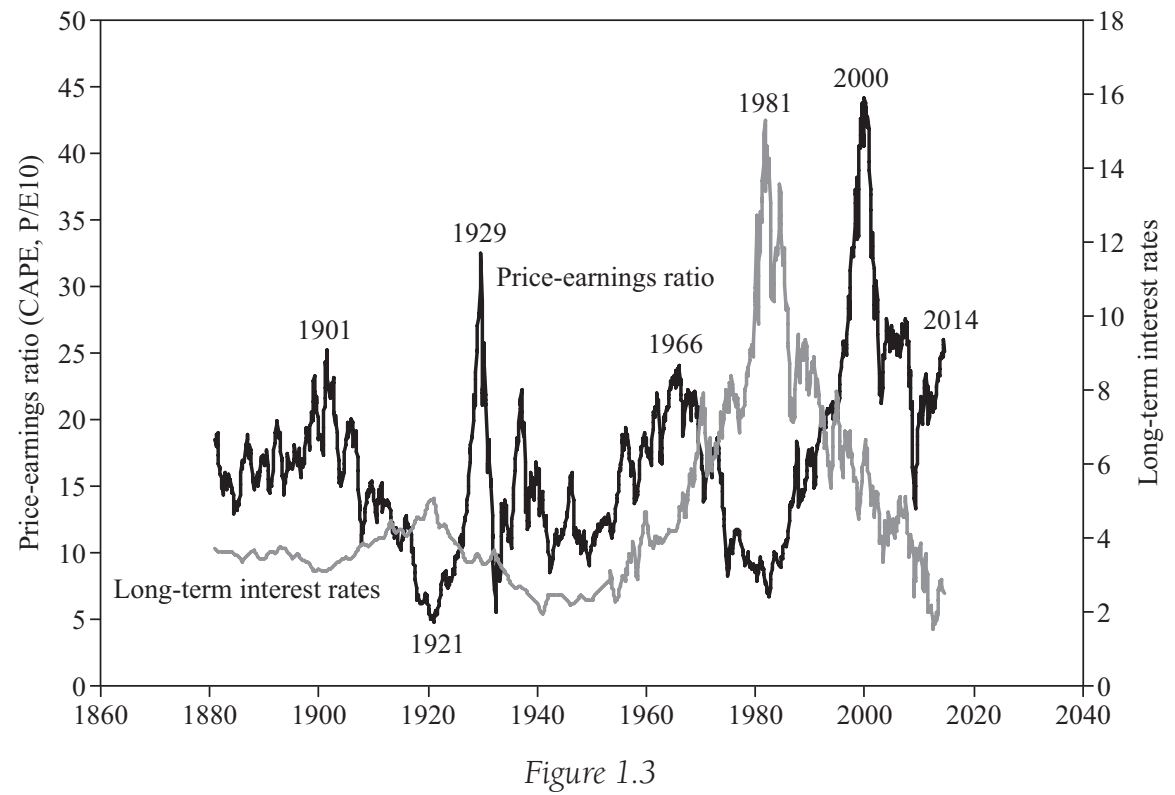

\section{U.S. Cyclically Adjusted Price-Earnings Ratio (CAPE) and Interest Rates, 1881-2014}

Price-earnings ratio, monthly, January 1881 to June 2014. Numerator: real (inflation-corrected) S\&P Composite Stock Price Index. Denominator: moving average over preceding ten years of real S\&P Composite earnings. Years of peaks are indicated. Source: Author's calculations using data shown in Figure 1.1. Interest rate is the yield of long-term U.S. government bonds (nominal), January 1881 to June 2014 (author's splicing of two historical long-term interest rate series). See also note 7.

Certainly, expansive talk about the new millennium at the time encouraged such a story. But it would have been more reasonable, judging from the cyclical behavior of earnings throughout history, to predict a reversal of such earnings growth.

The bust in corporate profits between 2000 and 2001, the biggest drop in profits in percentage terms since 1920-21, is certainly part of the story about the drop in the market. This drop certainly diminished support for the notion that the new high-tech economy was infallible. But there is a question of how to interpret the drop in earnings. As we shall discuss in Chapter 5, the drop in earnings could be seen in many dimensions, and in part, as just an indirect consequence of the changes in investor psychology that produced the decline in the market. Part of the crash in earnings after 2000 was also just a technical accounting reaction to the stock price decline, since companies were required by accounting rules to deduct from earnings the impairment in value of some 
(c) Copyright, Princeton University Press. No part of this book may be distributed, posted, or reproduced in any form by digital or mechanical means without prior written permission of the publisher.

of their stock market holdings, holdings that were far reduced in value after the crash in the stock market.

\section{Other Periods of High Price Relative to Earnings}

There have been three earlier times when the price-earnings ratio as shown in Figure 1.3 attained high values, though never as high as the 2000 value. The first time was in June 1901, when the price-earnings ratio reached a high of 25.2. This might be called the "Twentieth Century Peak," since it came around the time of the celebration of the new century. (The advent of the twentieth century was celebrated on January 1, 1901, not January 1, 1900.) $)^{10}$ This peak occurred as the aftermath of a doubling of real earnings within five years, following the U.S. economy's emergence from the depression of the 1890s. ${ }^{11}$ The 1901 peak in the price-earnings ratio occurred after a sudden spike in the ratio, which took place between July 1900 and June 1901, an increase of 43\% in eleven months. A turn-of-the-century optimism appeared-associated with expansive talk about a prosperous and high-tech future.

After 1901, there was no pronounced immediate downtrend in real prices, but for the next decade, prices bounced around or just below the 1901 level and then fell. By June 1920, the stock market had lost 67\% of its June 1901 real value. The average real return in the stock market (including dividends) was $3.4 \%$ a year in the five years following June 1901, barely above the real interest rate. The average real return (including dividends) was $4.4 \%$ a year in the ten years following June 1901, 3.1\% a year in the fifteen years following June 1901, and $-0.2 \%$ a year in the twenty years following June $1901 .{ }^{12}$ These returns are lower than we generally expect from the stock market, though had one held on into the 1920s, returns would have improved dramatically.

The second instance of a high price-earnings ratio occurred in September 1929, the high point of the market in the 1920s and the second-highest ratio of all time. After the spectacular bull market of the 1920s, the ratio attained a value of 32.6. As we all know, the market tumbled from this high, with a real drop in the S\&P Index of $80.6 \%$ by June 1932 . The decline in real value was profound and long-lasting. The real S\&P Composite Index did not return to its September 1929 value until December 1958. The average real return in the stock market (including dividends) was $-13.1 \%$ a year for the five years following September $1929,-1.4 \%$ a year for the next ten years, $-0.5 \%$ a year for the next fifteen years, and $0.4 \%$ a year for the next twenty years. ${ }^{13}$

The third instance of a high price-earnings ratio occurred in January 1966, when the ratio as shown in Figure 1.3 reached a local maximum of 24.1. We might call this the "Kennedy-Johnson Peak," drawing as it did on the prestige and charisma of President John Kennedy and the help of his vice-president and successor, Lyndon Johnson. This peak came after a dramatic bull market 
(c) Copyright, Princeton University Press. No part of this book may be distributed, posted, or reproduced in any form by digital or mechanical means without prior written permission of the publisher.

and after a five-year real price surge of $52 \%$ from May 1960. This surge, which took the price-earnings ratio to its local maximum, corresponded to a surge in real earnings of $36 \%$. The market reacted to this earnings growth as if it expected the growth to continue, but of course it did not. Real earnings increased little in the next decade. Real prices bounced around near their January 1966 peak, surpassing it somewhat in 1968, then falling sharply back after 1973. Real stock prices were down 56\% from their January 1966 value by December 1974 and would not be back up to the January 1966 level until May 1992. The average real return in the stock market (including dividends) was $-2.6 \%$ a year for the five years following January $1966,-1.8 \%$ a year for the next ten years, $-0.5 \%$ a year for the next fifteen years, and $1.9 \%$ a year for the next twenty years.

We see evidence in these past episodes of temporarily high price that irrational exuberance is not a new thing, and that such episodes do not end well. The high CAPE—higher than any peaks save 1929, 2000, and 2007 as of this writing in 2014-warrants some concern, though we do not yet know the aftermath of this time. We will return to a discussion of the predictive power of the price-earnings ratio in Chapter 11.

\section{Worries about Irrational Exuberance}

As reflected in the first edition of this book, in 2000 I thought that most people I met, from all walks of life, were puzzled over the apparently high levels of the stock market. It seemed that they were unsure whether the market levels made any sense, or whether they were indeed the result of some human tendency that might be called irrational exuberance. They wondered whether the high levels of the stock market might have reflected unjustified optimism, an optimism that might have pervaded our thinking and affected many of our life decisions. They seemed unsure what to make of any small market downturn, wondering whether the previous market psychology could ever return.

Even Alan Greenspan seemed unsure. He made his "irrational exuberance" speech two days after I had testified before him and the Federal Reserve Board that market levels were irrational, but a mere seven months later he reportedly took an optimistic "new era" position on the economy and the stock market. In fact, Greenspan has always been very cautious in his public statements, and did not commit himself to either view. A modern version of the prophets who spoke in riddles, Greenspan likes to pose questions rather than make pronouncements. In the public exegesis of his remarks it was often forgotten that, when it comes to such questions, even he did not know the answers.

Years after its 2000 peak, the market is back up near its peak levels in real terms. The news media in 2007 and 2014 seemed to relish trumpeting new records set (in nominal terms) by the stock market. And yet, deep down, 
(c) Copyright, Princeton University Press. No part of this book may be distributed, posted, or reproduced in any form by digital or mechanical means without prior written permission of the publisher.

people know that the market was then and is now highly priced, and they are uncomfortable with this fact.

Lacking answers from our wisest experts, many are inclined to turn to the wisdom of the markets to answer our questions, to use the turns of the stock market as fortune tellers use tea leaves. But before we begin assuming that the market is revealing some truth about this new era, it behooves us to reflect on the real determinants of market moves and how these market moves, in their effects, filter through the economy and our lives.

Many of those real determinants are in our minds. They are the "animal spirits" that John Maynard Keynes thought drove the economy, and that were the subject of my 2009 book Animal Spirits with George Akerlof. ${ }^{14}$ These same animal spirits drive other markets, such as the bond market and the real estate market, to which we now turn as other case studies of speculative behavior, before we begin our analysis of the causes of such behavior in Part One of this book. 